\title{
In Silico Study on Sulfated and Non-Sulfated Carbohydrate Chains from Proteoglycans in Cnidaria and Their Interaction with Collagen
}

\author{
Thomas Eckert $^{1,2}$, Sabine Stötzel ${ }^{1}$, Monika Burg-Roderfeld ${ }^{1}$, Judith Sewing ${ }^{3,4}$, Thomas Lütteke $^{1}$, \\ Nikolay E. Nifantiev ${ }^{5}$, Johannes F. G. Vliegenthart ${ }^{6}$, Hans-Christian Siebert ${ }^{1,7}$ \\ ${ }^{1}$ Institut für Biochemie und Endokrinologie, Veterinärmedizinische Fakultät, Justus-Liebig-Universität, Gießen, Germany \\ ${ }^{2}$ Klinik für Geburtshilfe, Gynäkologie und Andrologie, Veterinärmedizinische Fakultät, Justus-Liebig-Universität, Gießen, Germany \\ ${ }^{3}$ Coastal Research \& Management, Kiel-Holtenau, Germany \\ ${ }^{4}$ Institut für Virologie und Zellbiologie, Lübeck Universität, Lübeck, Germany \\ ${ }^{5}$ N. D. Zelinsky Institute of Organic Chemistry, Russian Academy of Sciences, Moscow, Russian Federation \\ ${ }^{6}$ Department of Bio-Organic Chemistry, Bijvoet Center for Biomolecular Research, Utrecht University, Utrecht, The Netherlands \\ ${ }^{7}$ RI-B-NT - Research Institute of Bioinformatics and Nanotechnology, Kiel, Germany \\ Email:info@ri-b-nt.de
}

Received January 10, 2012; revised February 17, 2012; accepted March 21, 2012

\begin{abstract}
Proteoglycans and collagen molecules are interacting with each other thereby forming various connective tissues. The sulfation pattern of proteoglycans differs depending on the kind of tissue and/or the degree of maturation. Tissues from Cnidaria are suitable examples for exploration of the effects in relation to the presence and the absence of sulfate groups, when studying characteristic fragments of the long proteoglycan carbohydrate chains in silico. It has been described that a non-sulfated chondroitin appears as a scaffold in early morphogenesis of all nematocyst types in Hydra. On the other hand, sulfated glucosaminoglycans play an important role in various developmental processes of Cnidaria. In order to understand this biological phenomenon on a sub-molecular level we have analysed the structures of sulfated and non-sulfated proteoglycan carbohydrate chains as well as the structure of diverse collagen molecules with computational methods including quantum chemical calculations. The strong interactions between the sulfate groups of the carbohydrates moieties in proteoglycans and positively charged regions of collagen are essential in stabilizing various Cnidaria tissues but could hinder the nematocyst formation and its proper function. The results of our quantum chemical calculations show that the sulfation pattern has a significant effect on the conformation of chondroitin structures under study.
\end{abstract}

Keywords: Quantum Chemical Calculations; Proteoglycans; Collagen; Atom Force Microscopy; Cnidaria

\section{Introduction}

Proteoglycans represent a special class of glycoproteins, which are heavily glycosylated. These bio-macromolecules consist of a core protein with one or more covalently attached glycosaminoglycan (GAG) chain(s). The glycosaminoglycan chains are long, linear carbohydrate polymers that are negatively charged under physiological conditions, due to the occurrence of sulfate and uronic acid groups. Chondroitin sulfate is the most prevalent GAG. Its linkage geometry between predominant disaccharide units is GlcA $\beta 1-3 \mathrm{GalNAc} \beta 1$. The monomeric residues are GlcA or GlcA(2S) and GalNAc or GalNAc $(4 S)$ or GalNAc $(6 S)$ or GalNAc $(4 S, 6 S)$ [1]. Beside chondroitin, hyaluronan is another GAG, which consists of the same disaccharide units as chondroitin sulfate but is the only
GAG that is exclusively non-sulfated. Since the sulfation pattern in Cnidaria differs depending on its locus, tissue or organelle type [2] we used various tissue probes from these organisms and analysed them with AFM methods as well as with optic microscopy techniques. This strategy allows an optimal preparation of collagen-proteoglycan samples and enables to estimate the influence of sulfation on tissue differentiation. Cnidaria are Anthozoa (corals, sea anemones, sea fanes), Hydrozoa (hydra), Cubozoa (box jellyfishes) and Scyphozoa (jellyfishes). Like in tissues of other animals sulfated and non-sulfated proteoglycan carbohydrate chains have been found in Cnidaria $[2,3]$. The proteoglycan carbohydrate chains consist of numerous saccharide moieties. In order to design reliable models of fragments of these large carbohydrate chains we have generated its diverse building blocks with the high- 
est possible degree of accuracy in the calculation process. First, five different hexasaccharides have been constructed, which can be considered as the characteristic fragments of the carbohydrate proteoglycan chains. The impact of the presence and the absence of sulfate groups on the hydrogen bond network in these carbohydrate chains was studied with quantum chemical calculations.

The intra-molecular interaction mechanisms could be described by molecular modelling calculations on various levels of theory when performing quantum chemical calculations. We have analysed five different hexasaccharides with various sulfation profiles, which share the common carbohydrate structure L-4-en-4-deoxy-thr Hexp-A( $\alpha \mathrm{l}-3)$ $\operatorname{GalNAc}(\beta 1-4) \operatorname{GlcA}(\beta 1-3) \operatorname{Gal}(\beta 1-3) \operatorname{Gal}(\beta 1-4)$ Xylp- $\beta$ (see Figure 1). Residue L-4-en-4-deoxy-thr-HexpA-unit $A$ on Figure 1 an unsaturated derivative of D-glucuronic acid) is formed within the degradation of polysaccharide chains. Parent compound I does not contain any sulfate group. Three compounds are mono-sulfated, two of them have an $O$-sulfate group at either C6 (II) or C4 (III) of the GalNAc residue. The third mono-sulfated compound (IV) has an $O$-sulfate group at $\mathrm{C} 4$ of the Gal residue preceding the GlcA residue, whereas the GalNAc is not sulfated. The disulfated compound (V) has sulfate groups at $\mathrm{C} 4$ of both the Gal residue preceding GlcA and the GalNAc residue. The structural heterogeneity of these hexasaccharides reflects the polydiversity in the linkage region of the chondroitin sulfate chains: L-4-en-4-deoxythrHexpA $(\alpha \mathrm{l}-3) \mathrm{GalNAc}(4-O$-or6- $O$-sulfate $)(\beta 1-4) \mathrm{GlcA}$ and L-4-en-4-deoxy-t $h r H \operatorname{expA}(\alpha \mathrm{l}-3)$ GalNAc(4- $O$-or6- $O$-sulfate) $(\beta 1-4) \mathrm{GlcA}(\beta 1-3) \mathrm{Gal}-\mathrm{NAc}$ (4-O-sulfate), respectively. We have used the quantum chemical approach for a precise determination of energies and conformational angles [4-8].

\section{Materials and Methods}

\section{Methods for theoretical calculation and modeling}

At first, we have generated a conformation analysis of the trisaccharide building blocks using the force field CHARMM27 and refined the conformations with the semi-empirical method AM1 with the Hyperchem 8.0 prof. packet [9]. The results are a prerequisite for our density functional theory (DFT) calculations. The models were used as starting structures for DFT calculations at a deeper level of theory with the B3LYP/6-31G* approach implemented in Gaussian 03 [10]. We have also performed calculations with B3LYP/6-31+G ${ }^{*}$ and could show that the extension of time by a factor of 5 to 10 was the only significant result. Considerable alterations in the calculated structures did not occur. The constructed fragments were grouped together to five different hexasaccharides (I)-(V) and calculated again with DFT using B3LYP/ $6-31 G^{*}$. The docking calculations between the glycans and colla- gen were performed with the Molegro trial version [11]. The following geometric and energy optimizations were carried out again with the force field CHARMM27 in- cluded in the Hyperchem 8.0 prof. packet [9].

Preparation of exumbrella tissue samples

Exumbrella of salted eatable jellyfish Rhopilema esculentum was washed several times in distilled water and then equilibrated for at least one hour in PBS. Small pieces were prepared for cryo-cutting by embedding in Tissue $\mathrm{Tek}^{\circledR}$ (Sakura) and freezed at $-20^{\circ} \mathrm{C}$. Cryo-cutting was carried out with a Leica CM 3050S machine. For DAPIstaining (Roche diagnostics) a $1 \mu \mathrm{g} / \mathrm{ml}$ solution in PBS was dropped on the slices, incubated at room temperature for half an hour in darkness and then rinsed with PBS. The optic microscopy study was performed using fluorescence dyes. The AFM measurements have been performed as described in literature [12]. For the AFM analysis of the exumbrella tissue of salted eatable jellyfish.

Rhopilema esculentum

We have dissolved $2.8 \mathrm{mg}$ in $1 \mathrm{ml}$ PBS buffer and diluted with pure water to a concentration corresponding to $10 \mathrm{ng} / \mathrm{ml}$. From this probe we laid $50 \mu \mathrm{l}$ on the mica plates and dried it about 20 min under nitrogen.

\section{Results and Discussion}

\section{Calculations}

The quantum-chemical calculations were started with core glycan structures and consisting of trisaccharide building blocks. These building blocks were used for the construction of five different Glycan structures Figure 1 I-V, which differ by their sulfation pattern as described above. It was our aim to calculate precisely defined fragments of the huge proteoglycan carbohydrate chains in order to generate the building blocks for an extensive in silico interaction study with diverse collagen molecules occurring in different tissues of Cnidaria. The calculated energy minimum structures are shown in Figures 2 (I)-(V).

In a first step, the energies and conformations of trisaccharides with and without sulfate groups were calculated with Gaussian 03/Hyperchem 8.0, (Preliminary calculations: AM1, Gnorm =0.00001). The quantum chemical

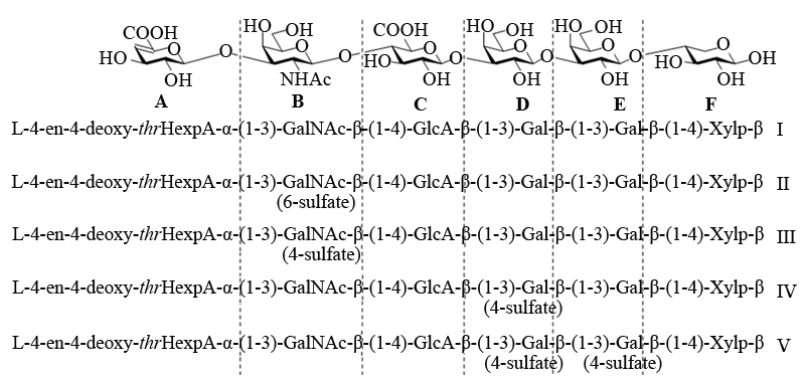

Figure 1. Schematic presentation of the hexasaccharides I-V. 


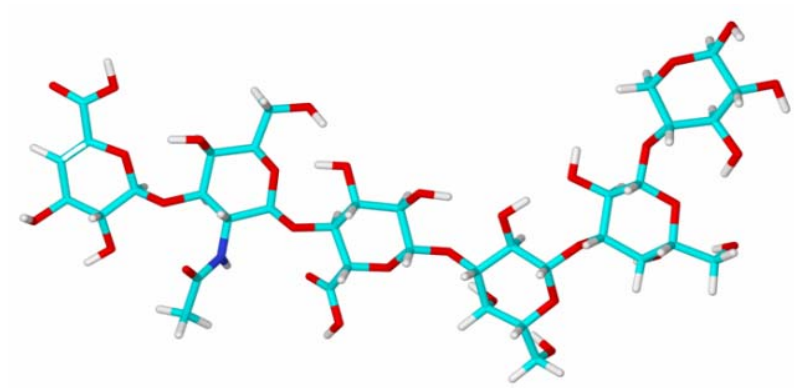

(I)

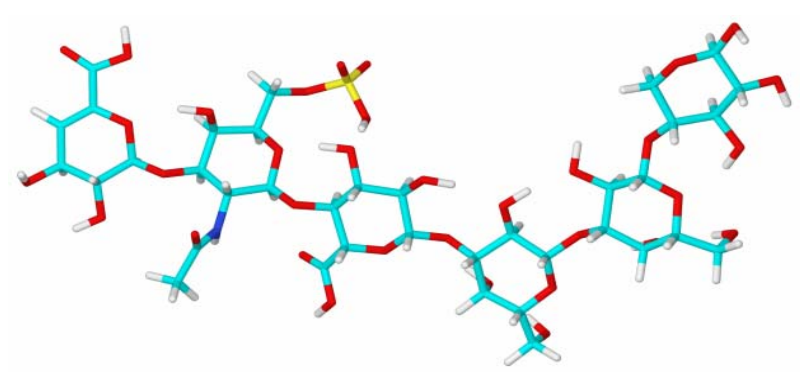

(II)

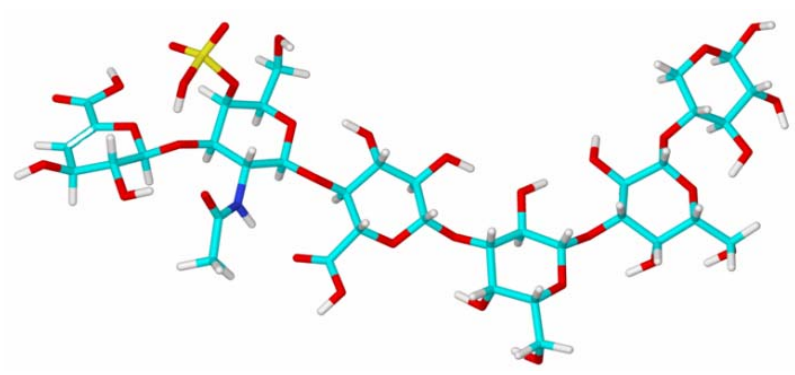

(III)

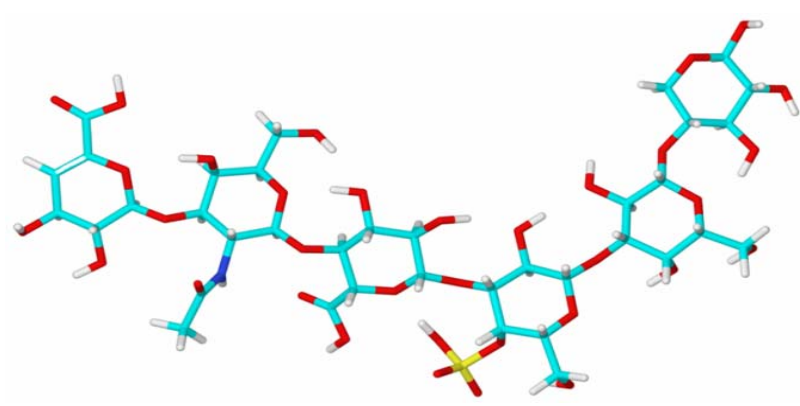

(IV)

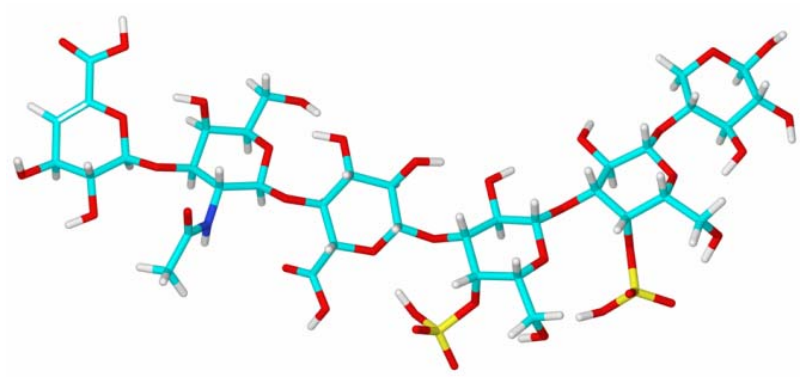

(V)

Figure 2. Minimal energy conformations of hexasaccharides (I); (II); (III); (IV) and (V).
Under physiological $\mathrm{pH}$ conditions the $\mathrm{COO}^{-}$and $\mathrm{SO}_{4}^{-}$ groups are de-protonated. However, in our DFT calculations using $\mathrm{B} 3 \mathrm{LYP} / 6-31 \mathrm{G}^{*}$ we have chosen the non-ionized state. It turned out that the protonated state corresponds to the conditions in the water environment much better than the de-protonated state in the vacuum. Certain energy minima are overestimated others are underestimated when quantum chemical calculations are carried out under vacuum conditions. Independent of the protonation state certain energy-minima are adopted under classical conditions when running MD simulations in a water environment. For the in silico molecular docking studies the de-protonated Glycan forms have been used since the electrostatic interactions between the Glycans and the proteins are of major importance.

The calculated glycosidic linkages are shown in Table 1. Corresponding trisaccharides have been constructed and energetically minimized with semi-empirical methods (AM1). The models were used as starting structures for DFT (Density Functional Theory) calculations in a deeper level of theory with the RB3LYP/6-31 $\mathrm{G}^{*}$ approach.

The trimeric saccharides with the lowest energies were combined to the larger hexameric saccharide chains of Glycans I-V. The energies and conformational angles $\Phi$ and $\Psi$ were again calculated with the DFT approach at the RB3LYP/6-31G ${ }^{*}$ level of theory.

The conformation of Glycan I (Figure 2) listed in Table $\mathbf{2}$ is mainly stabilized by hydrogen bonds, which are displayed for all five glycan stuctures in Table 3 . In the case of Glycan II (Figure 2), the sulfate group on Gal-NAc in position 6 has no significant effect on the $\Phi$ and $\Psi$ angles due to the high mobility of the sulfate group. Therefore, $\Phi$ and $\Psi$ angles similar to those calculated for Glycan (I) occur in Table 2. The sulfate group in 4 position of GalNAc, which is present in Glycan III (Figure 2) suppresses hydrogen bond formation. Therefore, the $\Phi 1$ - and $\Psi 1$-angle values differ significantly from those of Glycan $\mathbf{I}$. The sulfate group also influences the $\mathrm{CH}_{2} \mathrm{OH}$ group of the GalNAc, which has an impact on the $\Phi 2$ and $\Psi 2$ angle values. When calculating the glycosidic angles of Glycan IV (Figure 2) it is obvious that the presence of a sulfate group of the Gal-residue influences the glycosidic angles $\Phi 3$ and $\Psi 3$ between GlcA and Gal. In the case of the disulfated Glycan $\mathbf{V}$ (Figure 2) the glycosidic angles $\Phi 3$ und $\Psi 3$ are similar to those of Glycan IV, as expected. However, the second sulfate group of the second galactose (unit E) causes an alteration in the $\Phi 4$ and $\Psi 4$ glycosidic angles due to the hydrogen bonding between this sulfate group and the $\mathrm{CH}_{2} \mathrm{OH}$ group of the other galactose (unit D). As has already been shown for fucobiosides and fucoidans [13], it is possible to determine conformational differences in dependence of the sulfation profile. In contrast to the polysaccharides from Cnidaria, which are discussed here, fucoidans are a group of highly sulfated polysaccharides 
Table 1. Energies and conformational characteristics (angles in degrees) of trisaccharides corresponding to the fragments of hexasaccharides I-V.

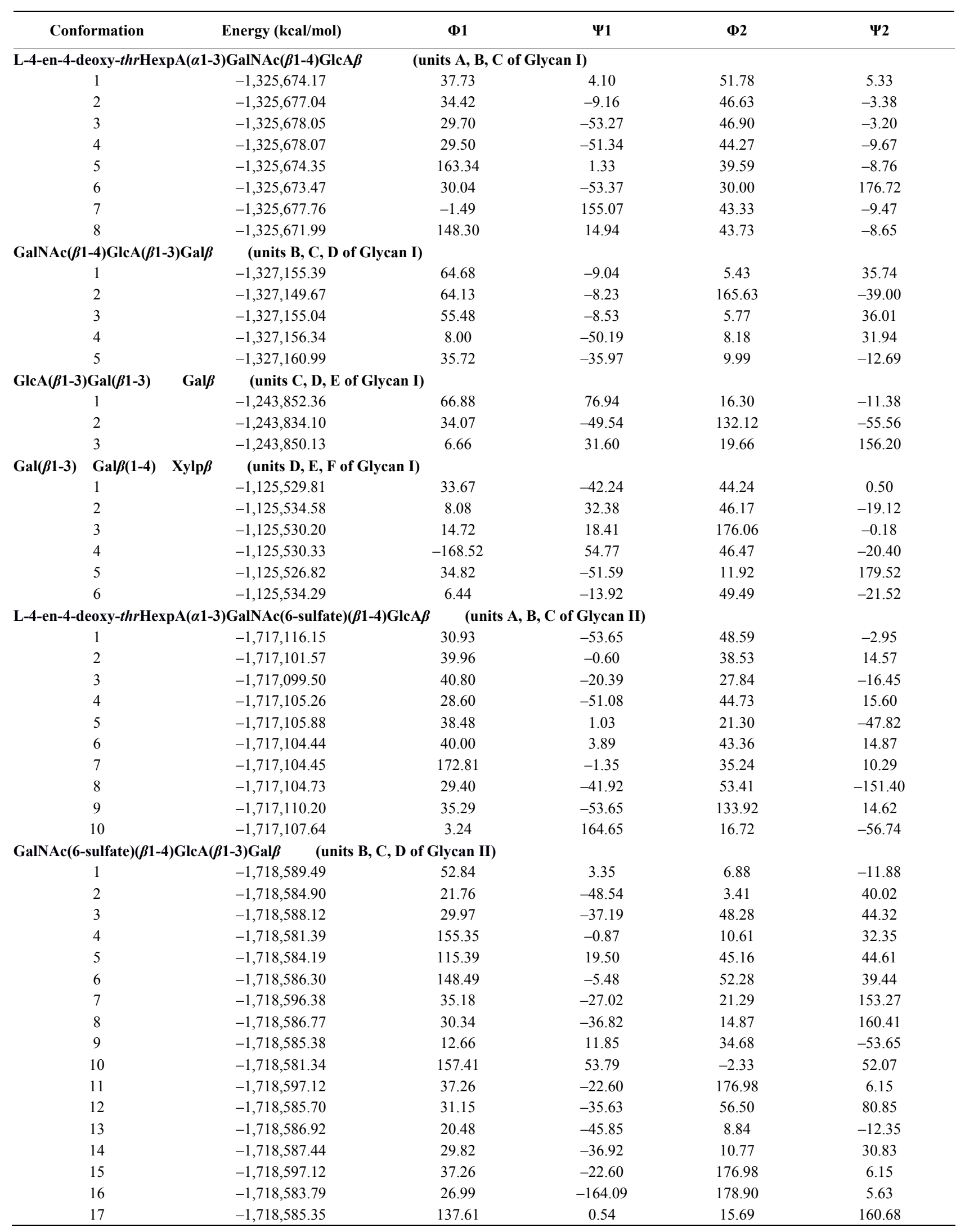


Continued

\begin{tabular}{|c|c|c|c|c|c|}
\hline \multirow{2}{*}{$\begin{array}{c}\overline{\operatorname{GlcA}(\beta 1-3) \mathrm{Gal}(\boldsymbol{\beta 1 - 3}) \mathrm{Gal} \boldsymbol{\beta}} \\
1\end{array}$} & \multicolumn{5}{|c|}{ (units C, D, E of Glycan II) } \\
\hline & $-1,243,852.36$ & 66.88 & 76.94 & 16.30 & -11.38 \\
\hline 2 & $-1,243,834.10$ & 34.07 & -49.54 & 132.12 & -55.56 \\
\hline 3 & $-1,243,850.13$ & 6.66 & 31.60 & 19.66 & 156.20 \\
\hline \multicolumn{6}{|c|}{ (units D, E, F of Glycan II) } \\
\hline 1 & $-1,125,529.81$ & 33.67 & -42.24 & 44.24 & 0.50 \\
\hline 2 & $-1,125,534.58$ & 8.08 & 32.38 & 46.17 & -19.12 \\
\hline 3 & $-1,125,530.20$ & 14.72 & 18.41 & 176.06 & -0.18 \\
\hline 4 & $-1,125,530.33$ & -168.52 & 54.77 & 46.47 & -20.40 \\
\hline 5 & $-1,125,526.82$ & 34.82 & -51.59 & 11.92 & 179.52 \\
\hline 6 & $-1,125,534.29$ & 6.44 & -13.92 & 49.49 & -21.52 \\
\hline \multicolumn{6}{|c|}{ L-4-en-deoxy-thrHexpA( $\alpha 1-3)$ GalNAc(4-sulfate) $(\beta 1-4) G i c A \beta \quad$ (units A, B, C of Glycan III) } \\
\hline 1 & $-1,717,104.54$ & 39.84 & 0.78 & 30.07 & -23.65 \\
\hline 2 & $-1,717,109.00$ & 45.82 & -11.80 & 33.87 & -19.89 \\
\hline 3 & $-1,717,104.09$ & -15.48 & -28.56 & 37.21 & -11.59 \\
\hline 4 & $-1,717,108.57$ & 12.33 & 34.24 & -3.30 & 173.06 \\
\hline 5 & $-1,717,104.93$ & 168.99 & -0.92 & 35.73 & -15.71 \\
\hline 6 & $-1,717,097.74$ & 42.38 & -3.74 & 34.32 & 171.61 \\
\hline 7 & $-1,717,105.52$ & 47.15 & -17.11 & 162.52 & -3.91 \\
\hline \multicolumn{6}{|c|}{ 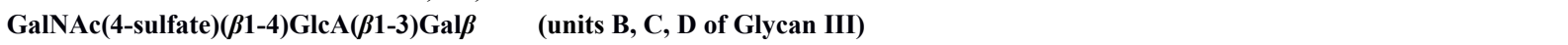 } \\
\hline 1 & $-1,7185,88.10$ & 44.49 & -13.74 & 13.43 & 28.55 \\
\hline 2 & $-1,718,585.83$ & 45.40 & -12.44 & -177.26 & 1.80 \\
\hline 3 & $-1,718,587.51$ & 32.99 & -35.88 & 11.02 & 31.10 \\
\hline 4 & $-1,718,584.85$ & 21.60 & -48.98 & 3.47 & -9.62 \\
\hline $\operatorname{GlcA}(\beta 1-3) \mathrm{Gal}(\beta 1-3) \mathrm{Gal} \beta$ & (units $\mathrm{C}, \mathrm{D}, \mathrm{E}$ of $\mathrm{C}$ & & & & \\
\hline 1 & $-1,243,852.36$ & 66.88 & 76.94 & 16.30 & -11.38 \\
\hline 2 & $-1,243,834.10$ & 34.07 & -49.54 & 132.12 & -55.56 \\
\hline 3 & $-1,243,850.13$ & 6.66 & 31.60 & 19.66 & 156.20 \\
\hline \multicolumn{6}{|c|}{$\operatorname{Gal}(\beta 1-3) \operatorname{Gal}(\beta 1-4) X y l p \beta \quad$ (units D,E,F of glycan III) } \\
\hline 1 & $-1,125,529.81$ & 33.67 & -42.24 & 44.24 & 0.50 \\
\hline 2 & $-1,125,534.58$ & 8.08 & 32.38 & 46.17 & -19.12 \\
\hline 3 & $-1,125,530.20$ & 14.72 & 18.41 & 176.06 & -0.18 \\
\hline 4 & $-1,125,530.33$ & -168.52 & 54.77 & 46.47 & -20.40 \\
\hline 5 & $-1,125,526.82$ & 34.82 & -51.59 & 11.92 & 179.52 \\
\hline 6 & $-1,125,534.29$ & 6.44 & -13.92 & 49.49 & -21.52 \\
\hline \multicolumn{6}{|c|}{ L-4-en-deoxy-thrHexpA( $(\alpha 1-3) \operatorname{GalNAc}(\beta 1-4) G l c A \beta \quad$ (units A, B, C of Glycan IV) } \\
\hline 1 & $-1,325,674.17$ & 37.73 & 4.10 & 51.78 & 5.33 \\
\hline 2 & $-1,325,677.04$ & 34.42 & -9.16 & 46.63 & -3.38 \\
\hline 3 & $-1,325,678.05$ & 29.70 & -53.27 & 46.90 & -3.20 \\
\hline 4 & $-1,325,678.07$ & 29.50 & -51.34 & 44.27 & -9.67 \\
\hline 5 & $-1,325,674.35$ & 163.34 & 1.33 & 39.59 & -8.76 \\
\hline 6 & $-1,325,673.47$ & 30.04 & -53.37 & 30.00 & 176.72 \\
\hline 7 & $-1,325,677.76$ & -1.49 & 155.07 & 43.33 & -9.47 \\
\hline 8 & $-1,325,671.99$ & 148.30 & 14.94 & 43.73 & -8.65 \\
\hline \multicolumn{6}{|c|}{$\operatorname{GalNAc}(\beta 1-4) \operatorname{GlcA}(\beta 1-3) \operatorname{Gal}(4-s u l f a t e) \beta \quad$ (units B,C,D of Glycan IV) } \\
\hline 1 & $-1,718,582.52$ & 29.07 & -47.06 & 56.34 & 48.57 \\
\hline 2 & $-1,718,592.73$ & 39.27 & -13.78 & 46.36 & -21.85 \\
\hline 3 & $-1,718,576.04$ & 30.36 & -32.25 & -172.26 & -12.42 \\
\hline 4 & $-1,718,590.74$ & 36.66 & -14.39 & 165.01 & 5.37 \\
\hline 5 & $-1,718,591.20$ & 135.47 & 19.91 & 57.97 & 55.41 \\
\hline 6 & $-1,718,586.04$ & 37.75 & -13.98 & 36.05 & -4.63 \\
\hline \multicolumn{6}{|c|}{$\operatorname{GlcA}(\beta 1-3) G a l(4-s u l f a t e)(\beta 1-3) G a l \beta \quad$ (units C, D, E of Glycan IV) } \\
\hline 1 & $-1,635,282.35$ & 42.76 & -25.88 & 14.63 & -7.15 \\
\hline 2 & $-1,635,285.69$ & 27.59 & -27.19 & 4.64 & -5.96 \\
\hline 3 & $-1,635,281.14$ & -13.74 & -46.86 & 47.75 & 37.06 \\
\hline 4 & $-1,635,286.47$ & 24.20 & -24.86 & 12.07 & 29.60 \\
\hline 5 & $-1,635,285.70$ & 27.68 & -27.20 & 4.61 & -5.99 \\
\hline 6 & $-1,635,284.44$ & 29.05 & -31.40 & 177.58 & 6.48 \\
\hline 7 & $-1,635,276.23$ & 5.93 & -6.16 & 7.40 & -9.21 \\
\hline 8 & $-1,635,284.60$ & -10.95 & -13.13 & 7.27 & -8.74 \\
\hline
\end{tabular}


Continued

\begin{tabular}{|c|c|c|c|c|c|}
\hline \multicolumn{6}{|c|}{ 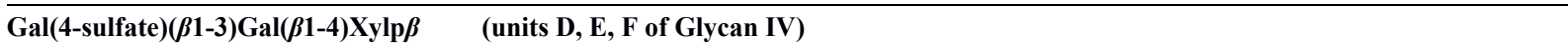 } \\
\hline 1 & $-1,516,955.89$ & 12.30 & -28.74 & 80.32 & -8.80 \\
\hline 2 & $-1,516,950.45$ & 51.44 & 31.15 & 28.80 & -47.75 \\
\hline 3 & $-1,516,955.61$ & 11.43 & 29.19 & 28.83 & -44.02 \\
\hline 4 & $-1,516,959.46$ & 6.64 & -11.57 & 49.09 & -22.07 \\
\hline \multicolumn{6}{|c|}{ L-4-en-deoxy-thrHexpA( $\alpha 1-3)$ GalNAc $(\beta 1-4) G l c A \beta \quad$ (units A, B, C of Glycan V) } \\
\hline 1 & $-1,325,674.17$ & 37.73 & 4.10 & 51.78 & 5.33 \\
\hline 2 & $-1,325,677.04$ & 34.42 & -9.16 & 46.63 & -3.38 \\
\hline 3 & $-1,325,678.05$ & 29.70 & -53.27 & 46.90 & -3.20 \\
\hline 4 & $-1,325,678.07$ & 29.50 & -51.34 & 44.27 & -9.67 \\
\hline 5 & $-1,325,674.35$ & 163.34 & 1.33 & 39.59 & -8.76 \\
\hline 6 & $-1,325,673.47$ & 30.04 & -53.37 & 30.00 & 176.72 \\
\hline 7 & $-1,325,677.76$ & -1.49 & 155.07 & 43.33 & -9.47 \\
\hline 8 & $-1,325,671.99$ & 148.30 & 14.94 & 43.73 & -8.65 \\
\hline \multicolumn{6}{|c|}{$\operatorname{GalNAc}(\beta 1-4) \operatorname{GlcA}(\beta 1-3)$ Gal(4-sulfate) $\beta \quad$ (units B, C, D of Glycan V) } \\
\hline 1 & $-1,718,582.52$ & 29.07 & -47.06 & 56.34 & 48.57 \\
\hline 2 & $-1,718,592.73$ & 39.27 & -13.78 & 46.36 & -21.85 \\
\hline 3 & $-1,718,576.04$ & 30.36 & -32.25 & -172.26 & -12.42 \\
\hline 4 & $-1,718,590.74$ & 36.66 & -14.39 & 165.01 & 5.37 \\
\hline 5 & $-1,718,591.20$ & 135.47 & 19.91 & 57.97 & 55.41 \\
\hline 6 & $-1,718,586.04$ & 37.75 & -13.98 & 36.05 & -4.63 \\
\hline \multicolumn{6}{|c|}{$\operatorname{GlcA}(\beta 1-3) G a l(4-s u l f a t e)(\beta 1-3) G a l(4-s u l f a t e) \beta \quad$ (units $C, D, E$ of Glycan V) } \\
\hline 1 & $-2,026,722.96$ & 43.15 & -30.52 & 43.36 & -31.17 \\
\hline 2 & $-2,026,723.02$ & 13.17 & 27.27 & 41.71 & -30.23 \\
\hline 3 & $-2,026,711.65$ & 9.11 & 29.55 & 55.98 & 37.49 \\
\hline 4 & $-2,026,720.45$ & -168.38 & 12.31 & 41.43 & -31.07 \\
\hline 5 & $-2,026,720.03$ & 44.08 & -28.74 & 25.44 & -45.21 \\
\hline 6 & $-2,026,722.95$ & 43.15 & -30.51 & 43.39 & -31.22 \\
\hline 7 & $-2,026,719.90$ & 48.84 & 29.31 & 175.46 & -0.47 \\
\hline 8 & $-2,026,720.60$ & -157.78 & 39.25 & 26.77 & -40.07 \\
\hline 9 & $-2,026,719.34$ & 11.23 & 32.53 & 176.52 & 2.70 \\
\hline 10 & $-2,026,715.53$ & 171.39 & 3.09 & 177.87 & 6.53 \\
\hline 11 & $-2,026,714.42$ & 49.39 & 23.29 & 44.50 & 100.00 \\
\hline 12 & $-2,026,716.69$ & 48.68 & 25.46 & 43.83 & 75.77 \\
\hline 13 & $-2,026,712.26$ & -26.94 & -16.68 & 27.89 & -45.95 \\
\hline \multicolumn{6}{|c|}{$\operatorname{Gal}(4-$ sulfate $)(\beta 1-3)$ Gal(4-sulfate) $(\beta 1-4) X y l p \beta \quad$ (units D, E, F of Glycan V) } \\
\hline 1 & $-1,908,378.29$ & 8.37 & 28.49 & 27.66 & -46.69 \\
\hline 2 & $-1,908,381.53$ & 8.33 & 29.82 & 31.43 & -29.16 \\
\hline 3 & $-1,908,391.38$ & -29.89 & 30.79 & 29.11 & 10.42 \\
\hline 4 & $-1,908,387.17$ & -33.03 & 28.34 & -4.11 & 175.65 \\
\hline 5 & $-1,908,389.08$ & 29.54 & 37.09 & 28.50 & -32.32 \\
\hline 6 & $-1,908,391.01$ & 13.08 & 7.50 & 177.11 & -2.12 \\
\hline 7 & $-1,908,386.78$ & 10.43 & 25.95 & 15.07 & -178.49 \\
\hline 8 & $-1,908,388.69$ & 170.04 & 5.79 & 176.06 & -2.58 \\
\hline 9 & $-1,908,396.97$ & 49.58 & 62.71 & 38.08 & -28.43 \\
\hline
\end{tabular}

Table 2. Calculated conformational angles $\Phi$ and $\Psi$ for inter-unit linkages of Glycans I-V (in degrees).

\begin{tabular}{|c|c|c|c|c|c|c|c|c|c|c|}
\hline Glycan & $\Phi 1$ & $\Psi 1$ & $\Phi 2$ & $\Psi 2$ & Ф3 & $\Psi 3$ & $\Phi 4$ & $\Psi 4$ & $\Phi 5$ & $\Psi 5$ \\
\hline I & 29.86 & -52.21 & 44.27 & -9.80 & 1.81 & -13.79 & 6.82 & -13.47 & 49.83 & -22.01 \\
\hline II & 30.58 & -52.99 & 47.13 & -2.60 & 1.41 & -9.96 & 6.71 & -10.68 & 49.22 & -21.58 \\
\hline III & 46.25 & -12.17 & 32.59 & -22.67 & 0.62 & -12.12 & 8.07 & -11.78 & 50.46 & -22.02 \\
\hline IV & 29.63 & -50.78 & 45.71 & -8.28 & -29.49 & -16.70 & 9.15 & -10.76 & 50.78 & -21.91 \\
\hline $\mathbf{V}$ & 30.35 & -52.64 & 47.38 & -8.55 & -30.22 & -14.58 & 30.62 & -40.40 & 49.96 & -23.85 \\
\hline
\end{tabular}


Table 3. Hydrogen-bonds (in $\mathrm{nm}$ ) in the structures of the Glycan I - V.

\begin{tabular}{|c|c|c|c|c|c|}
\hline Hydrogen-bonds & Glycan I & Glycan II & Glycan III & Glycan IV & Glycan V \\
\hline Ring-O unit A with $\mathrm{OH}-4$ unit $\mathrm{B}$ & 0.220 & 0.219 & - & 0.223 & 0.219 \\
\hline O-1 unit A with $\mathrm{OH}-4$ unit B & 0.258 & 0.261 & - & 0.256 & 0.259 \\
\hline Sulfate-H unit B with O-1 unit A & - & - & 0.186 & - & - \\
\hline OH-6 unit B with O-5 unit B & - & - & 2.43 & - & - \\
\hline OH-6 unit B with O-3 unit C & 0.242 & - & - & 0.245 & 0.244 \\
\hline Ring-O unit $\mathrm{B}$ with $\mathrm{OH}-3$ unit $\mathrm{C}$ & 0.196 & 0.208 & 0.193 & 0.195 & 0.194 \\
\hline O-1 unit $\mathrm{B}$ with $\mathrm{OH}-3$ unit $\mathrm{C}$ & 0.252 & 0.244 & 0.266 & 0.252 & 0.253 \\
\hline Sulfate- $\mathrm{H}$ unit $\mathrm{B}$ with $\mathrm{O}-3$ unit $\mathrm{C}$ & - & 0.164 & - & - & - \\
\hline $\mathrm{NH}$ unit $\mathrm{B}$ with carboxy-O unit $\mathrm{C}$ & - & - & 0.205 & - & - \\
\hline $\mathrm{OH}-2$ unit $\mathrm{C}$ with $\mathrm{O}-2$ unit $\mathrm{D}$ & 0.199 & 0.194 & 0.197 & 0.191 & 0.193 \\
\hline $\mathrm{O}-1$ unit $\mathrm{C}$ with $\mathrm{OH}-4$ unit $\mathrm{D}$ & 0.219 & 0.219 & 0.219 & - & - \\
\hline Sulfate- $\mathrm{H}$ unit $\mathrm{D}$ with ring- $\mathrm{O}$ unit $\mathrm{C}$ & - & - & - & 0.182 & 0.180 \\
\hline OH-6 unit D with O-4 unit D & 0.196 & 0.196 & 0.196 & 0.217 & 0.209 \\
\hline $\mathrm{OH}-2$ unit $\mathrm{D}$ with $\mathrm{O}-2$ unit $\mathrm{E}$ & 0.199 & 0.195 & 0.198 & 0.197 & 0.277 \\
\hline $\mathrm{O}-1$ unit $\mathrm{D}$ with $\mathrm{OH}-4$ unit $\mathrm{E}$ & 0.222 & 0.221 & 0.223 & 0.224 & - \\
\hline Sulfate-H ring E with O-6 ring D & - & - & - & - & 0.165 \\
\hline $\mathrm{OH}-6$ unit $\mathrm{E}$ with sulfate- $\mathrm{O}$ unit $\mathrm{E}$ & - & - & - & - & 0.200 \\
\hline OH-6 unit E with O-4 unit E & 0.199 & 0.200 & 0.200 & 0.200 & 0.267 \\
\hline Ring-O unit $\mathrm{E}$ with $\mathrm{OH}-3$ unit $\mathrm{F}$ & 0.196 & 0.196 & 0.196 & 0.196 & 0.200 \\
\hline $\mathrm{OH}-2$ unit $\mathrm{F}$ with $\mathrm{O}-3$ unit $\mathrm{F}$ & 0.223 & 0.222 & 0.223 & 0.223 & 0.221 \\
\hline
\end{tabular}

of brown seaweeds, which have received increasing interest as readily available biopolymers having many promising biological activities. Another source of sulfated carbohydrates are marine fishes. The structural characterization, the anti-inflammatory and anticoagulant activity of chondroitin sulfates from cartilage of Atlantic salmon (Salmo salar), Greenland shark (Somniosus microcephalus), Blackmouth catshark (Galeus melastomus), Birdbeak dogfish (Deania calcea) and Arctic skate (Amblyraja hyperborea) have recently been described [14].

The absence or the presence of a sulfate group is not only important for the energetic minima of the Glycans, the interactions of the Glycans with collagen molecules also depend on the position of the sulfate groups. Therefore, we have highlighted these functional parts of the proteoglycan molecules in their homo-orbital presentations (Figure 3).

In relation to our docking studies it is remarkable that the sulfate groups with their significant HOMO orbitals are essential contact groups for various collagen molecules (Figures $\mathbf{4}$ and $\mathbf{5}$ ).

Molecular interaction partners of proteoglycans in Cnidaria tissues are mini-collagens with charged ends (Figure 4) [15] as well as triple-helical collagen fragments $[12,16]$. The positively charged contact points consist of Arg and Lys residues [12,15,16]. Also in the case of triple-helical collagen structures Arg residues are the most suited contact points (Figure 5).
We have performed in silico interaction studies of the five designed Glycan structures (Glycan I-V) and mini-collagen (Figure 4). In the same way we have studied the interactions between Glycans $\mathbf{I}-\mathbf{V}$ with triplehelical collagen structures (Figure 5). It turned out that the glycosidic angles $\Phi$ and $\Psi$, which correspond to the low-energy conformation of the ligand-free state differ slightly from those of the components interacting with the collagen molecules.

Complexes between mini-collagen fragments and characteristic Glycans (Figure 4) have been performed by a feasible molecular docking program (the Molegro trial version [11]). The same software was used for the docking studies, in which triple helical collagen fragments are interacting with the Glycan hexamers under study (Figure 5). The triple helical structure was taken from an Xray model of an integrin-collagen complex (1dzi. pdb) [16]. The Glycans and the Arg residues, which are preferentially interacting with the proteoglycan sulfate groups are highlighted in their van-der-Waals representation.

Mini-collagen molecules and small collagen fragments $[12,15,17-19]$ as well as longer collagen fragments $[12,17]$ are interacting in multiple manners with the Glycan structures under study. These results differ significantly from our observations concerning collagen integrin interactions [12]. Sophisticated microscopic techniques are needed to clarify how the absence and presence of sulfate groups in proteoglycans from Cnidaria trigger its morphogenesis. 


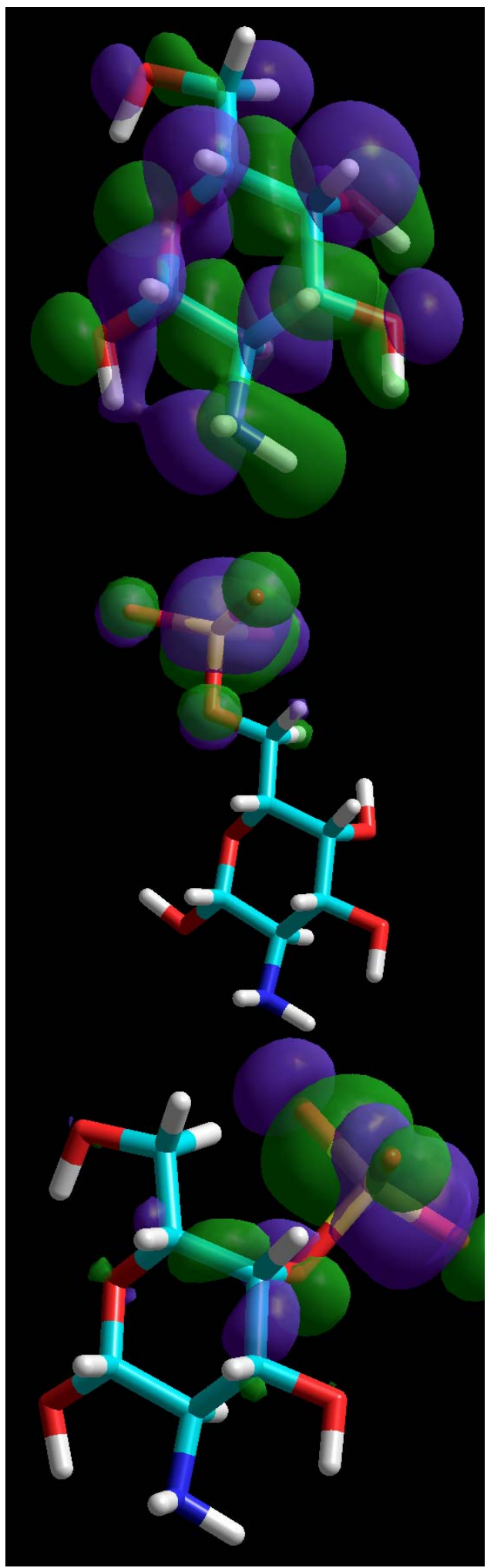

Figure 3. Homo-orbital presentation of GalNAc, non-sulfated (top) and sulfated at position 6 (middle) as well as at position 4 (bottom). The sulfate groups are charged. Orbitals have been calculated for the whole molecules. When a sulfate group is present the orbitals are located at the corresponding position.
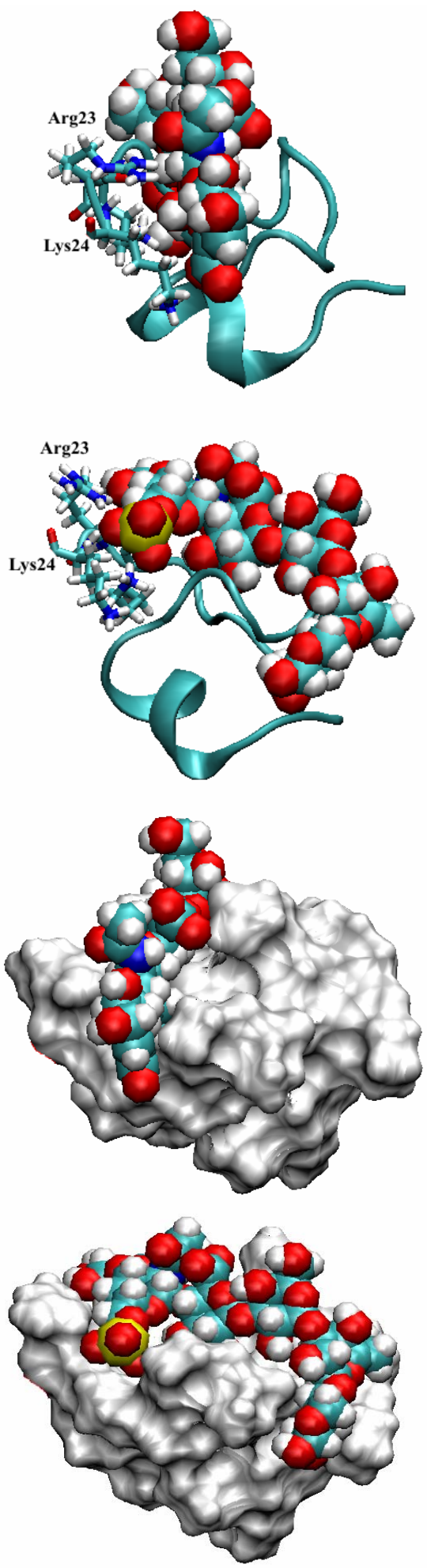

Figure 4. Mini-collagen fragment (1sop.pdb) $[15,17]$ in complex with non-sulfated Glycan I (top) and sulfated Glycan II (below the top) in their backbone presentations with highlighted Arg23 and Lys24 residues. The surface presentations are given in the same orientation: Gycan I (above bottom) and sulfated Glycan II (bottom). 


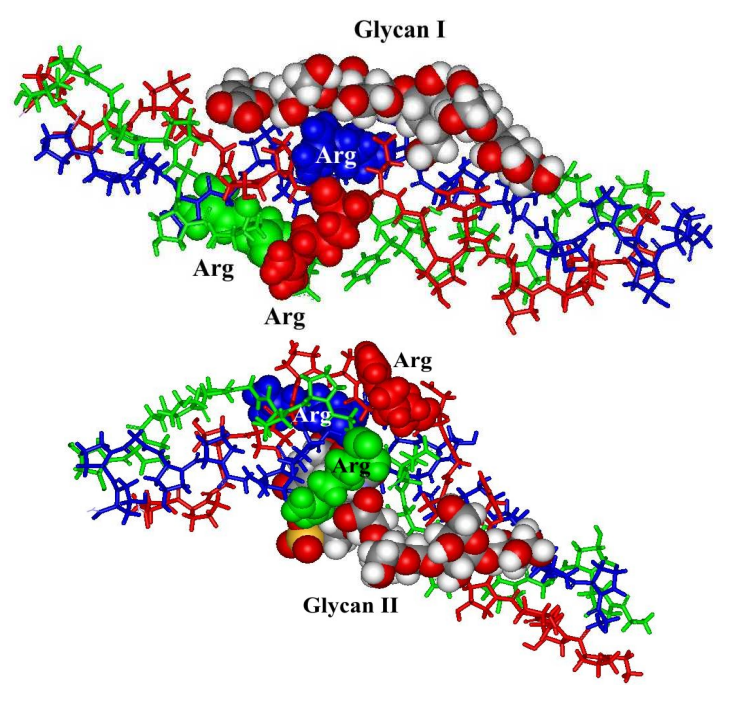

Figure 5. Triple-helical collagen structure in complex with Glycan I (top) and Glycan II (bottom).

Furthermore, the nematocyst discharge processes can be explained in a better way when the interaction mechanisms between non-sulfated proteoglycans and minicollagen molecules can be described on a sub-molecular level. In a nematocyst poly-gamma-glutamate rich minicollagens are synthesized during the formation of nematocyst capsules in Hydra [20]. Together with the available information about the differentiation process [21-25] a first step is made to simulate nematocyst discharge processes (coulomb explosions) as well as proteoglycan collagen interactions in cartilage tissues with computational methods. As outlined in two recent publications a solid knowledge about the structural properties of Glycan sulfate groups is a prerequisite for a detailed understanding in respect to their biological function [26,27].

\section{Results and Discussion}

\section{Experimental Part}

For the AFM analysis probes of the exumbrella tissue of salted eatable Rhopilema jellyfish were put on mica plates Figure 6 (top). We compared the AFM probes with probes from the same exumbrella tissue, which were prepared for light microscopic analysis by Dapi staining Figure 6 (bottom). After treatment with an aprotic solvent we recognized that the addition of DMSO can disturb and destroy the collagen-proteoglycan network so that only small tissue pieces remain (Figure 7).

In our present study the quantum chemical calculations and the computational docking analysis of the five Glycans are flanked by an AFM analysis of various jellyfish tissues. It is described in the literature that hydrolyzed collagen can induce chondrogenic differentiation of equine adipose tissue-derived stromal cells [28]. Although the impact of proteoglycan fragments in such differentiation
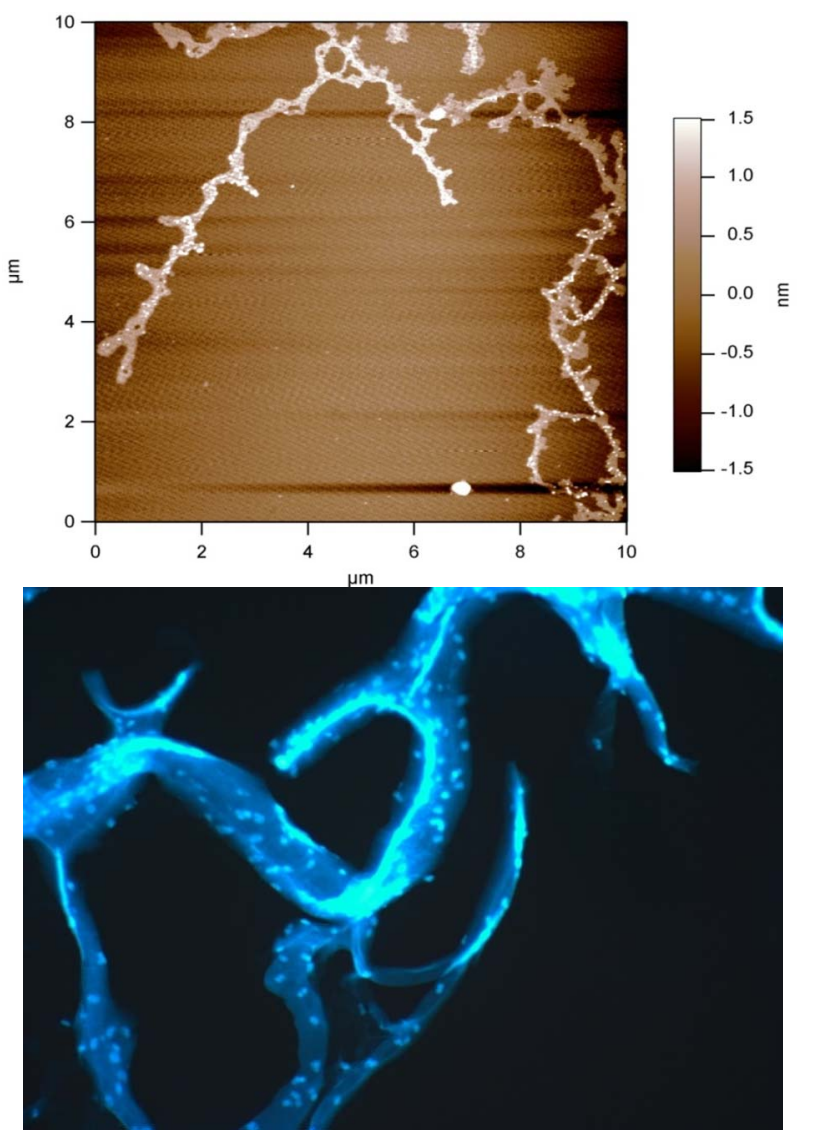

Figure 6. AFM and fluorescent pictures of the exumbrella tissue of salted eatable Rhopilema jellyfish.

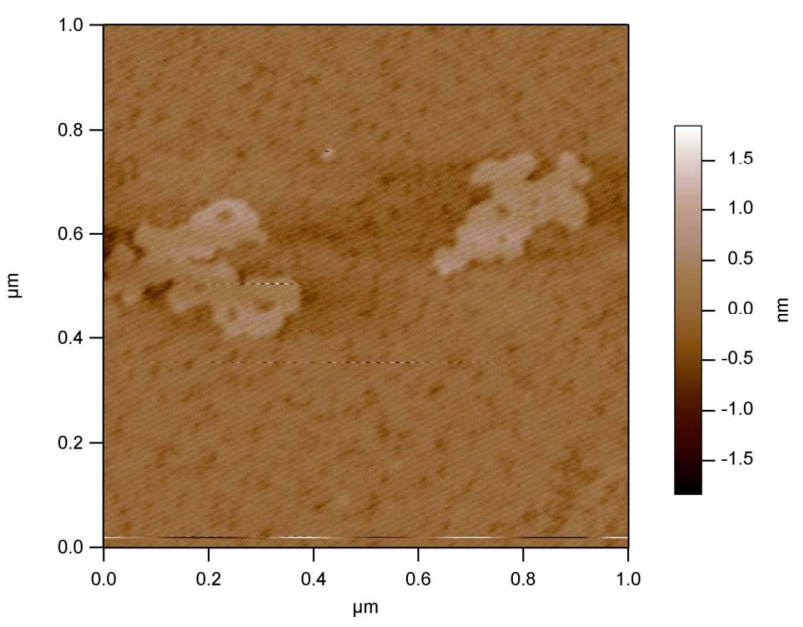

Figure 7. Impact of DMSO on the exumbrella tissue of the jellyfish Rhopilema esculentum. Only small pieces of the jellyfish tissue remain in the aprotic solvent. The sample was dried under nitrogen.

processes is unknown it is now possible to combine the theoretically derived data about the collagen-proteoglycan interactions with results obtained by AFM and light microscopic techniques (Figure 8). After this study the theoretical background, which allows us a better defined 

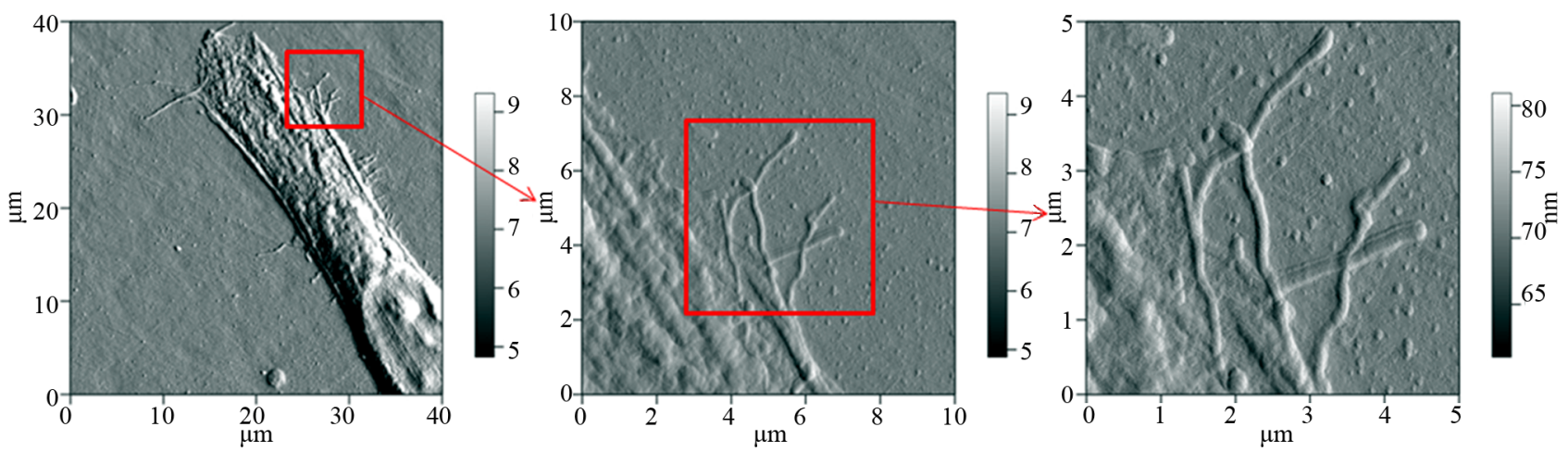

Figure 8. AFM pictures of an equine mesenchymal stem cell (cultured on a collagen surface). The middle and right picture shows a detailed presentation of their cilia.

discussion of the influence of collagen fragments and proteoglycans from various species on a sub-molecular level. Equine mesenchymal stem cells can be cultured on various media consisting of collagen (Figure 8) or of collagen-proteoglycan mixtures. Thereby, considering studies of stem cells in hydra [29,30]. We recognized that the differentiation processes are strongly depending on the proteoglycan-collagen ratio of the growth media.

Beside the unspecific proteoglycan collagen interacttion our theoretical and experimental results argue in favor that for the stabilization of the nematocyst tissue also a specific carbohydrate binding protein, i.e. nematogalectin [31] must be present. However, this kind of galectin is only specific for non-sulfated carbohydrates as it is the case for galectins in general [32]. To summarize our studies we have opened new routes to investigate proteoglycan-collagen interactions at an atomic size-level, as described for collagen hydrolysates and collagen fragments from various species [33].

\section{Acknowledgements}

We thank Mr. Robert Drews at the Institut für Virologie und Zellbiologie at the Universität Lübeck for his kind assistance when generating fluorescent pictures of exumbrella tissues. Elements of the project are financed by the European Commission's Framework Program 7 (BIONMR-00007)-Bio-NMR grant: Jellyfish protein NMR (BIO-NMR-00007)-IEP.

\section{REFERENCES}

[1] T. De Beer, A. Inui, H. Tsuda, K. Sugahara and J. F. G. Vliegenthart, "Polydispersity in Sulfation Profile of Oligosaccharide Alditols Isolated from the Protein-Linkage Region and the Repeating Disaccharide Region of Chondroitin 4-Sulfate of Bovine Nasal Septal Cartilage," European Journal of Biochemistry, Vol. 240, No. 3, 1996, pp. 789-797. doi:10.1111/j.1432-1033.1996.0789h.X

[2] P. Adamczyk, C. Zenkert, P. G. Balasubramanian, S. Yamada, S. Murakoshi, K. Sugahara, J. S. Hwang, T. Gojo- bori, T. W. Holstein and S. Özbek, "A Non-Sulfated Chondroitin Stabilizes Membrane Tubulation in Cnidarian Organelles," The Journal of Biological Chemistry, Vol. 285, 2010, pp. 25613-25623. doi:10.1074/jbc.M110.107904

[3] S. Yamada, H. Morimoto, T. Fujisawa and K. Sugahara, "Glycosaminglycans in Hydra Magnipapillata (Hydrozoa, Cnidaria): Demonstration of Chondroitin in the Developing Nematocyst, the Sting Organelle, and Structural Characterizayion of Glycosaminoglycans," Glycobiology, Vol. 17, No. 8, 2007, pp. 886-894. doi:10.1093/glycob/cwm051

[4] H.-C. Siebert, E. Tajkhorshid and J. Dabrowski, "Barrier to Rotation around the $\mathrm{C}_{\mathrm{sp}}{ }^{2}-\mathrm{C}_{\mathrm{sp}}{ }^{2}$ Bond of the Ketoaldehyde Enol Ether $\mathrm{MeC}(\mathrm{O})==\mathrm{CH}-\mathrm{OEt}$ as Determined by ${ }^{13} \mathrm{C} \mathrm{NMR}$ and $\mathrm{AB}$ Initio Calculation," The Journal of Physical Chemistry A, Vol. 105, No. 3, 2001, pp. 8488-8494. doi:10.1021/jp004476g

[5] J. H. van Lenthe, D. H. W. de Boer, R. W. A. Havenith, R. Schauer and H.-C. Siebert, "AB Initio Calculations on Various Sialic Acids Provide Valuable Information about Sialic Acid-Specific Enzymes," Journal of Molecular Structure: THEOCHEM, Vol. 667, No. 19-3, 2004, pp. 29-37. doi:10.1016/j.theochem.2004.01.013

[6] M. Remko and M. Hricovíni, "Theoretical Study of Structure and Properties of Hexuronic Acid and D-Glucosamine Structural Units of Glycosaminoglycans," Structural Chemistry, Vol. 18, No. 5, 2007, pp. 537-547. doi:10.1007/s11224-007-9181-y

[7] M. Hricovíni, E. Scholtzová and F. Bízik, "B3LYP/6$311++\mathrm{G}^{* *}$ Study of Structure and Spin-Spin Coupling Constant in Heparin Disaccharide," Carbohydrate Research, Vol. 342, No. 10, 2007, pp. 1350-1356. doi:10.1016/j.carres.2007.03.020

[8] E. Scholtzová, P. Mach and M. Hricovíni, "Structure of Sulfated Monosaccharides Studied by Quantum Chemical Methods," Molecules, Vol. 8, No. 11, 2003, pp. 770-779. doi: $10.3390 / 81100770$

[9] “Hyperchem Professional 8.0," Hypercube, Inc., Gainesville, 2007.

[10] M. J. Frisch, et al., "Gaussian 03, Revision B.03," Gaussian, Inc., Pittsburgh, 2003.

[11] “Molegro-Trial Version 3.0.0," 2008. 
[12] H.-C. Siebert, M. Burg-Roderfeld, T. Eckert, S. Stötzel, U. Kirch, T. Diercks, M. J. Humphries, M. Frank, R. Wechselberger, E. Tajkhorshid and S. Oesser, "Interaction of tne $\alpha 2 \mathrm{~A}$ Domain of Integrin with Small Collagen Fragments," Protein \& Cell, Vol. 1, No. 4, 2010, pp. 393405.

[13] A. G. Gerbst, N. E. Ustuzhanina, A. A. Grachev, E. A. Khatuntseva, D. E. Tsvetkov, A. S. Shashkov, A. I. Usov, M. E. Preobrazhenskaya, N. A. Ushakova and N. E. Nifantiev, "Synthesis, NMR and Conformational Studies of Fucoidan Fragments. V.[1] Linear 4,4',4"'-Tri-O-Sulfated and Parent Non-Sulfated $(1 \rightarrow 3)$-Fucotrioside Fragments," Journal of Carbohydrate Chemistry, Vol. 22, No. 2, 2003, pp. 109-122. doi:10.1081/CAR-120020481

[14] V. B. Krylov, A. A. Grachev, N. E. Ustyuzhanina, N. A. Ushakova, M. E. Preobrazhenskaya, N. I. Kozlova, M. N. Portsel, I. N. Konovalova, V. U. Novikov, H.-C. Siebert, A. S. Shashkov and N. E. Nifantiev, "Preliminary Structural Characterization, Anti-Inflammatory and Anticoagulant Activities of Chondroitin Sulfates from Marine Fish Cartilage," Russian Chemical Bulletin, Vol. 60, 2011, pp. 746-753.

[15] E. Pokidysheva, A. G. Milbradt, S. Meier, C. Renner, D. Haussinger, H. P. Bachinger, L. Moroder, S. Grzesiek, T. W. Holstein, S. Ozbek and J. Engel, "The Structure of the Cys-Rich Terminal Domain of Hydra Minicollagen, Which Is Involved in Disulfide Networks of the Nematocyst Wall," The Journal of Biological Chemistry, Vol. 279, 2004, pp. 30395-30401. doi:10.1074/jbc.M403734200

[16] J. Emsley, G. Knight, R. Farndale, M. Barnes and R. Liddington, "Structural Basis of Collagen Recognition by Integrin $\alpha 2 \beta 1$, , Cell, Vol. 101, No. 1, 2000, pp. 47-56. doi:10.1016/S0092-8674(00)80622-4

[17] A. G. Milbradt, C. Boulègue, L. Moroder and C. Renner, "The Two Cysteine-rich Head Domains of Minicollagen from Hydra Nematocysts Differ in their Cystine Framework and Overall Fold Despite an Identical Cysteine Sequence Pattern," Journal of Molecular Biology, Vol. 354, No. 3, 2005, pp. 591-600. doi:10.1016/j.jmb.2005.09.080

[18] S. Meier, D. Haussinger, E. Pokidysheva, H. P. Bachinger and S. Grzesiek, "Determination of a High-Precision NM$\mathrm{R}$ Structure of the Minicollagen Cysteine Rich Domain from Hydra and Characterization of Its Disulfide Bond Formation," FEBS Letters, Vol. 569, No. 1, 2004, pp. 112-116. doi:10.1016/j.febslet.2004.05.034

[19] J.-O. Lee, P. Rieu, M. A. Arnaout and R. Liddington, "Crystal Structure of the A Domain from the a SubUnit of Integrin CR3 (CD11 b/CD18)," Cell, Vol. 80, No. 4, 1995, pp. 631-638. doi:10.1016/0092-8674(95)90517-0

[20] S. Szczepanek, M. Cikala and C. N. David, "Poly-Gamma-Glutamate Synthesis during Formation of Nematocyst Capsules in Hydra," Journal of Cell Science, Vol. 115, 2002, pp. 745-751.

[21] S. Berking and K. Herrmann, "Formation and Discharge of Nematocysts Is Controlled by a Proton Gradient across the Cyst Membrane," Helgoland Marine Research, Vol. 60, No. 3, 2006, pp. 180-188. doi:10.1007/s10152-005-0019-y

[22] S. Özbek, P. G. Balasubramanian and T. W. Holstein, "Cnidocyst Structure and the Biomechanics of Discharge," Toxicon, Vol. 54, No. 8, 2009, pp. 1038-1045. doi:10.1016/j.toxicon.2009.03.006

[23] T. W. Holstein, M. Benoit, G. V. Herder, G. Wanner, C. N. David and H. E. Gaub, "Fibrous Mini-Collagens in Hydra Nematocysts," Science, Vol. 265, No. 5170, 1994, pp. 402-404. doi:10.1126/science.265.5170.402

[24] G. Tettamanti, A. Grimaldi, T. Congiu, G. Perletti, M. Raspanti, R. Valvassori and M. de Eguileor, "Collagen Reorganization in Leech Wound Healing," Biology of the Cell, Vol. 97, No. 7, 2005, pp. 557-568. doi:10.1042/BC20040085

[25] N. Ohta, M. Sato, K. Ushida, M. Kokubo, T. Baba, K. Taniguchi, M. Urai, K. Kihira and J. Mochida, "Jellyfish Mucin May Have Potential Disease-Modifying Effects on Osteoarthritis," BMC Biotechnology, Vol. 9, No. 98, 2009, pp. 1-11. doi:10.1186/1472-6750-9-98

[26] N. Sapay, E. Cabannes, M. Petitou and A. Imberty, "Molecular Modeling of the Interaction between Heparan Sulfate and Cellular Growth Factors: Bringing Pieces Together," Glycobiology, Vol. 21, No. 9, 2011, pp. 1181-1193. doi:10.1093/glycob/cwr052

[27] D. O. Croci, et al., "Fucans, but Not Fucomannoglucuronans, Determine the Biological Activities of Sulfated Polysaccharides from Laminaria Saccharina Brown Seaweed," PLOS ONE, Vol. 6, 2011, pp. 1-10. doi:10.1371/journal.pone.0017283

[28] O. Raabe, C. Reich, S. Wenisch, A. Hild, M. Burg-Roderfeld, H.-C. Siebert and S. Arnhold, "Hydrolyzed Fish Collagen Induced Chondrogenic Differentiation of Equine Adipose Tissue-Derived Stromal Cells," Histochemistry \& Cell Biology, Vol. 134, No. 6, 2010, pp. 545-554. doi:10.1007/s00418-010-0760-4

[29] U. Technau and R. E. Steele, "Evolutionary Crossroads in Developmental Biology: Cnidaria," Development, Vol. 138, 2011, pp. 1447-1458. doi:10.1242/dev.048959

[30] T. C. G. Bosch, "Hydra and the Evolution of Stem Cells," BioEssays, Vol. 31, No. 4, 2009, pp. 478-486. doi:10.1002/bies.200800183

[31] J. S. Hwang, Y. Takaku, T. Momose, P. Adamczyk, S. Özbek, K. Ikeo, K. Khalturin, G. Hemmrich, T. C. G. Bosch, T. W. Holstein, C. N. David and T. Gojobori, "Nematogalectin, a Nematocyst Protein with GlyXY and Galectin Domains, Demonstrates Nematocyte-Specific Alternative Splicing in Hydra," PNAS, Vol. 107, No. 43, 2010, pp. 18539-18544. doi:10.1073/pnas.1003256107

[32] A. M. Wu, T. Singh, J.-H. Liu, S. André, M. Lensch, H.-C. Siebert, M. Krzeminski, A. M. J. J. Bonvin, H. Kaltner, J. H. Wu and H.-J. Gabius, "Adhesion/Growth-Regulatory Galectins: Insights into Their Ligand Selectivity Using Natural Glycoproteins and Glycotopes, "Advances in Experimental Medicine and Biology, Vol. 705, 2011, pp. 117-141. doi:10.1007/978-1-4419-7877-6 7

[33] S. Stötzel, M. Schurink, H. Wienk, U. Siebler, M. Burg-Roderfeld, T. Eckert, B. Kulik, R. Wechselberger, J. Sewing, J. Steinmeyer, S. Oesser, R. Boelens and H.-C. Siebert, "Molecular Organization of Different Collagen Hydrolysates and Collagen Fragments as Revealed by a Combination of Atomic Force Microscopy (AFM) and Diffusion Ordered NMR Spectroscopy (DOSY)," ChemPhysChem, 2012. 